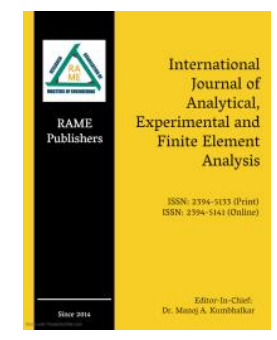

Omkar M. Nighul

Corresponding Author nighulomkar@gmail.com

Gajanan P. Tayade gajanantayade28@gmail.com

Vivekanand V. Waghmode waghmodevivekanand145@gmail.com

Rishikesh S. Kulthe kultherushi@gmail.com

Department of Mechanical Engineering, JSPM Narhe

Technical Campus, Pune 411041, Maharashtra, India

\title{
Health Monitoring and Automatic Sanitizer System for Organizations and Societies
}

Abstract - In the wake of the current pandemic. The outbreak of COVID-19 across the world has headed researchers, healthcare department and government authorities to work together and find an optimum solution to get rid of the disease and restrict its spread. The purpose of this research work is to create awareness about public safety and solutions by ways of health monitoring system, which will measure successfully the body temperature along with heart rate of a person and hence create a safer environment around. Primarily for this sensor (MLX90614) is used to measure the temperature as well as pulse sensor to monitor the heart rate, which is than interfaced with controller to control and monitor the data for smart communication. Also, touchless sanitizing device can be used to take precautionary measures which helps to sanitize the hands to decrease and till some extent kill the harmful virus. The paper basically focuses on the safety measures to be incorporated post lockdown. So, it's very effective to place the health monitoring system along with touchless sanitizer device at the entrance of any building.

Keywords- COVID-19, Government authorities, Health monitoring system, public safety sanitizing device.

\section{INTRODUCTION}

In the 20th century the three deadly pandemic diseases which shook the world were identified as SARS-CoV, MERS-CoV and Covid-19. SARS-CoV was first detected in China on November 2002 and subsequently spread to 30 countries. In this outbreak, 8096 cases were reported worldwide, with 774 deaths [1]. The second pandemic disease MERS coronavirus was the MERS-CoV which is a severe acute respiratory condition [2]. Though in 2019, there were 2494 cases of MERS-CoV reported worldwide with 858 related deaths from 27 countries [3]. The world witnessed the third deadliest pandemic disease COVID-19 of the genus beta coronavirus and is related to MERS and

Research Paper - Peer Reviewed

Published online - 30 March 2021

(C) 2021 RAME Publishers

This is an open access article under the CC BY 4.0 International License https://creativecommons.org/licenses/by/4.0/

Cite this article - Omkar M. Nighul, Gajanan P. Tayade, Vivekanand V. Waghmode, Rishikesh S. Kulthe, "Health Monitoring and Automatic Sanitizer System for Organizations and Societies", International Journal of Analytical, Experimental and Finite Element Analysis, RAME Publishers, vol. 8, issue 1, pp. 35-41, 2021.

https://doi.org/10.26706/ijaefea.1.8.20210307
SARS was reported in Wuhan- China and later spread extensively worldwide. As per World health organization, the coronavirus positive confirmed cases as of now across the world is 9473214 and death tolls to 484249 across 216 countries and still rising. [4].

One-third of the global population has been on coronavirus lockdown, the World health organization, which has officially confirmed the outbreak as pandemic has called on "all countries to proceed with endeavours in order to limit the number of cases and slow down the spread of the virus".

\section{A. After effects of Lockdown}

Scientists are exploring ways to exit out of this pandemic and get life back to normalcy. It is now very important to kick-start the economy and start with the business activities as before. In any case, we have to get back to normal and resume the activities as we did before. As William Sutherland, of the University of Cambridge, said "There will be a second wave of the virus". Hence social distancing, care and precautions are highly recommended. The focus of 
this research paper is to find some necessary steps to safeguard the employees and for that every organization would require taking necessary steps to curtail the spread of virus. The paper proposes precautionary measures by installing smart health monitoring system [5] along with non-contact hand sanitizer for employees joining after long period of lockdown.

Workers or employees ought to be entirely permitted to enter the gateway by screening their identity card at the entrance, such that the data monitoring can be directly linked to the employee database. The purpose is to contain the spread of the virus in a simple, fast, economical and efficient manner with certain necessary measures using sensors, hardware design, wireless networks and low-cost microcontrollers can pave way for new and innovative solutions. The serious issues in the ongoing juncture is to screen numerous patients whose wellbeing must be checked often as a piece of indicative method, the need for a financially savvy and advanced brisk response instruments have become intensely required when there is a flare-up of pandemic malady. Appropriate execution of such frameworks can give convenient alerts to doctors and their service can be activated in case of medical emergencies. Thus, this paper explores an innovative solution for a prototype with low cost and scalable health monitoring system along with a disinfectant system.

The purpose of the whole research revolves around the mechanism to detect fever, using non-contact temperature sensor and in the process if any individual is detected with high fever, a set alarm will alert the security systems and the individual would be sent to the infirmary for further test [6]. The individual's heart rate will also be monitored using the heart monitoring system which works on the principle of photoplethysmography. The change in flow of blood through any organ impacts the change in the light intensity through that organ. If the individual clears the screening, he will be allowed to use non-contact hand sanitizer where the ultrasonic sensor is enacted with advance controller to give signal to the sanitizer valve to open. With the current scenario and situation around, alcohol-based hand sanitizers are increasingly being used as disinfectants over standard

hand wash. This has resulted in improvement of hand hygiene with a reduction of infections/virus. Utilizing alcohol-based sanitizer, have proven to stop spreading the virus [7].

The design is essentially ordered into two main classifications: Design a health monitoring system \& a noncontact sanitizing system. Both the design techniques are mentioned below in $2 \& 3$ sections.

\section{DESIGN A HEALTH MONITORING SYSTEM}

Health monitoring system will measure body temperature and heart rate of a person. Raised body temperature is considered the most widely recognized indications of any sort of body infections [8]. Continuous monitoring of such changing parameter is challenging considering the burden of rehashed estimation of a person's internal heat levels, particularly when the individual may appear doing well [9]. Generally, the body temperature ranges from $36^{\circ} \mathrm{C}$ to $37^{\circ} \mathrm{C}$. Any range from $38^{\circ} \mathrm{C}$ up to $39^{\circ}$ $\mathrm{C}$ is considered as the beginning of fever. A lethal temperature of $39^{\circ} \mathrm{C}$ and above where medical treatment is an unquestionable requirement [10].

Along with fever detection heart rate monitoring is also essential. As people who have heart disease have less of cardiac reserve to be able to withstand the stress and fear which increased tremendously post pandemic spread [11]. Also, if a person is infected with virus, then the heart muscle can become inflamed and it can increase clotting and decrease flow of oxygen. Hence heart rate monitoring is also required.

\section{A. System Architecture}

The interconnections between various segments are explained using the design of frameworks. The patient interface is mapped by the temperature, pulse sensor and further processed by the controller. The information is then captured, and then appears on human machine interfacing (HMI) which is displayed on LCD and simultaneously if the temperature and heart rate exceeds the set range, the alarm triggers. The operation of the system is divided into four segments: Sense, monitor control and data transfer. Sensors are used to detect fever and heart rating of a person entering 
the building. The output signal from the sensor is controlled by the controllers which work on analog as well as digital signal. The control incorporates interfacing the sensors with the controllers and transmitting them wirelessly to the monitoring equipment using wifi module. WiFi module is used which transmit data wirelessly to health care expert. Lcd display is used to monitor the output obtained. Fig.2Health monitoring system.

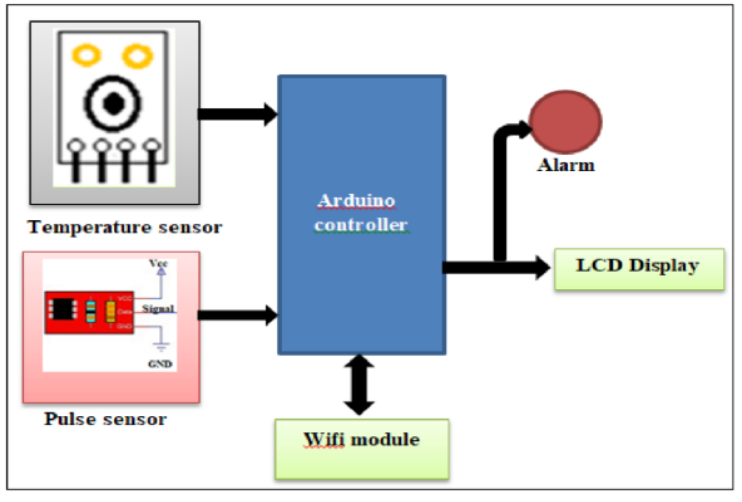

Figure 1. Health monitoring system

\section{B. System Components}

\section{Temperature Sensor}

The MLX90614 temperature sensor is an infra-red thermometer for non-contact temperature measurement and a signal conditioning processor [12].

As per the Stefan- Boltzmann law, any object that isn't beneath total zero $\left(0^{0} \mathrm{~K}\right)$ emits (non-human eye visible) light in the infrared spectrum that is directly proportional to its temperature. The infrared thermopile in the temperature sensor (MLX90614) senses how much infrared energy is being emitted by the subject and then produces an electrical signal proportional to it. It is a small size easy to integrate device with temperature variation range from $-400^{\circ} \mathrm{C}$ to $+850^{\circ} \mathrm{C}$ for sensor temperature.

\section{Pulse sensor}

The pulse sensor consists of three ports: Vcc supply, ground and signal. The description of Pulse sensor with Arduino is given in table 1 .

TABLE I

PULSE SENSOR WITH ARDUINO

\begin{tabular}{|l|l|l|}
\hline Pulse sensor & Arduino Uno & Description of pulse sensor \\
\hline Vcc Power & $5 \mathrm{~V}$ & Connected to 5V dc supply \\
\hline GND & GND & Connected to arduino ground \\
\hline Signal & Analog A0 & Pulsating analog signal \\
\hline
\end{tabular}

Pulse sensor works on the principle of optical method also known as photoplethysmography. On one side of the pulse sensor, led is placed along with an ambient light sensor and on the other side is an electronic integrated circuit which is responsible for amplifying the signal. To calculate the heart rate, the individual's fingertip is placed on the LED and accordingly the flow rate of the blood impacts the light emitting from the led. The heart rate can be calculated based upon the led display that blinks with each heartbeat per minute [13].

\section{Arduino}

The sensor output is connected to the analog pins of arduino controller. It converts the analog signal into digital signal. The digital signal is then interfaced with the lcd to display the output [14]. Controller is also connected with wifi module. The output from the controller can be wirelessly transmitted using ESP8266 wifi module to smart phones/devices.

\section{HMI, LCD Display/Alarm}

The human machine interface (HMI) is the interface between the machine and user to translate complex process variables into usable and actionable data. The reason for the HMI is to show effectively justifiable, real time, ongoing operational data. It is then interfaced with LCD and alarm. The liquid crystal display is an electronic device widely used to display digital output. If the temperature is greater than set value i.e. $37^{0} \mathrm{C}$ or heart rate exceeds $100 \mathrm{bpm}$ or goes below $60 \mathrm{bpm}$ then alarm gets activated and alerts the guard.

\section{WiFi module}

ESP8266 is a wifi enabled system on chip [15]. For wireless communication wifi module is used which can connect with Arduino board transmitter Tx and receiver Rx. Table 2 describe the connectivity between WiFi module with Arduino uno board.

TABLE II

WIFI MODULE WITH ARDUINO UNO

\begin{tabular}{|c|c|c|}
\hline Wifi module & Resistor & Arduino Uno \\
\hline Vcc Power & $10 \mathrm{~K}$ & $3.3 \mathrm{~V}$ \\
\hline CH_EN/Enable & $10 \mathrm{~K}$ & $3.3 \mathrm{~V}$ \\
\hline Tx/Transmitter & - & Pin 3 \\
\hline Rx/Receiver & $1 \mathrm{k}$ & Pin2 \\
\hline GND & - & GND \\
\hline
\end{tabular}


It consists of two general purpose input and output port GPIO-0 and GPIO-2, transmitter/receiver, supply, ground, channel enable pin CH_EN and reset to start.Fig.5-Wifi module.

The wifi module is used to send signal to the health expert if the health monitoring system detects abnormality. ESP8266 is a microcontroller which has the ability to function wifi related activities. Figure 6 shows alert to health expert.

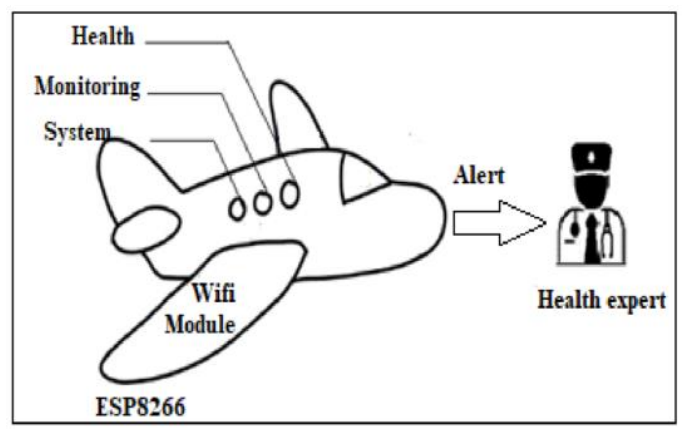

Figure 2. Alert to health expert

\section{NON-CONTACT SANITIZER SYSTEM}

Alcohol-based water free hand sanitizer dispensers (HSD) are an inexorably well known strategy for hand cleanliness and help prevent hospital-acquired infection (HAI). Subsequently in order to eradicate the spread of such dangerous virus sanitizer is useful [16].

\section{A. System Architecture}

A model of the proposed non-contact hand sanitizer dispensers can be given by the framework demonstrated. This portrayal of the framework introduced gives an understanding of how the proposed framework is being made. It mainly consists of ultrasonic sensor, Arduino uno board, relay, servomotor, water reservoir, hand sanitizer valve. An ultrasonic sensor is utilized to check the presence of hands beneath the sanitizer dispenser and also calculates the distance between the dispenser and hands. Then it passes the information to Arduino uno board which turns on the servomotor with the assistance of the relay and hand sanitizer dispenser valve gets opened. Reservoir is used to store the sanitizer. Figure 3 shows non-contact hand sanitizer dispensers.

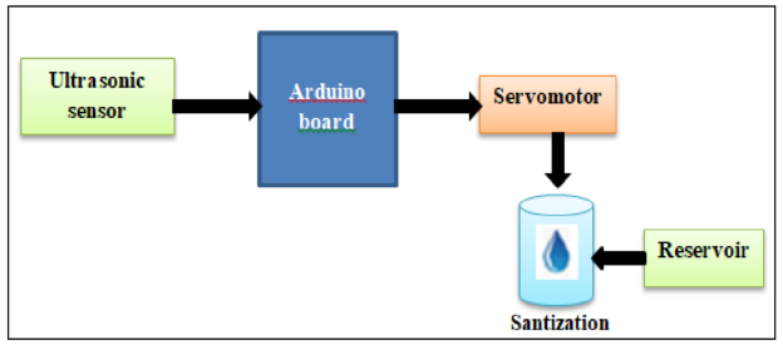

Figure 3. Non-contact hand sanitizer dispensers

\section{B. System components}

\section{Ultrasonic sensor}

An ultrasonic sensor is a device that estimates distance to an object using sound waves. It works by sending out a sound wave at ultrasonic frequency and bounce back if meets article. Figure 4 shows ultrasonic sensor.

To calculate the distance the time delay between transmission and receiving of the sound given:

Distance $=($ Speed of the sound $*$ Time delay $) / 2$

Ultrasonic sensor used here to detect the article by sending sound waves which hit the article and reflect the sound waves back to the receiving echo end [17]. Ultrasonic sensor detects frequency normally between the range 100 $\mathrm{KHz}$ to $50 \mathrm{MHz}$. Any article coming ahead of the ultrasonic sensor is detected and also calculates the distance from sending the signal to receiving the signal which then passed to the arduino controller.

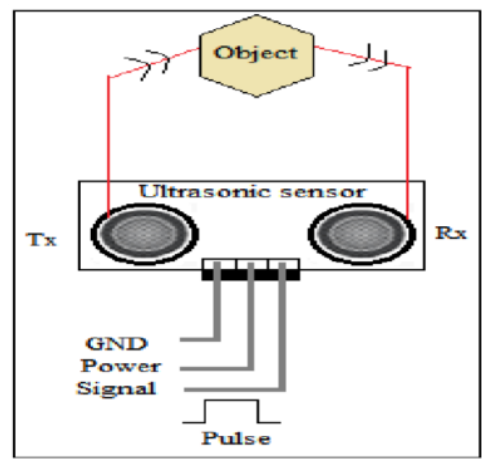

Figure 4. Ultrasonic sensor

\section{Servomotor}

Arduino gives signal to servomotor to rotate from 0 to $180^{\circ}$ as per requirement. If there is no or low signal from the controller then servomotor doesn't rotate and valve remains closed and when high signal is transmitted from the controller the servomotor rotates thus can open the dispenser valve. 


\section{RESULTS}

\section{A. Design a Health monitoring system}

Pulse sensor is used to detect the heartbeat in beats per minute of any individual. It consists of Vcc (5V supply), ground (GND), potentiometer (POT) and oscilloscope. The simulation is executed using simulation. Thus, potentiometer is used as the input and the obtained waveform is observed in the oscilloscope. Figure 5 shows Pulse sensor.

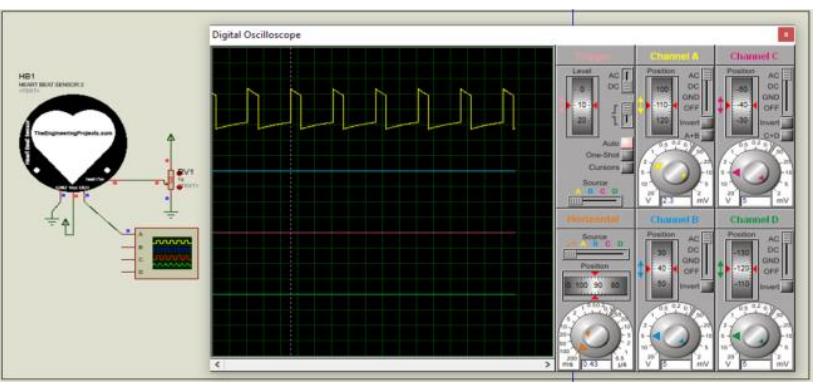

Figure 5. Pulse sensor

The pulse sensor output signal when connected to the arduino controller gives the output obtained and is then displayed. It indicates the heart beat per minutes. The output executed can be displayed online. Hence health expert can monitor the data of any individual for particular time and day monitored. Necessary measures can be taken at the earliest if any serious fluctuation occurs. Heart rate monitor is shown in figure 6. The information is constantly varying with respect to time which helps the health care expert to understand the situation comprehensively.

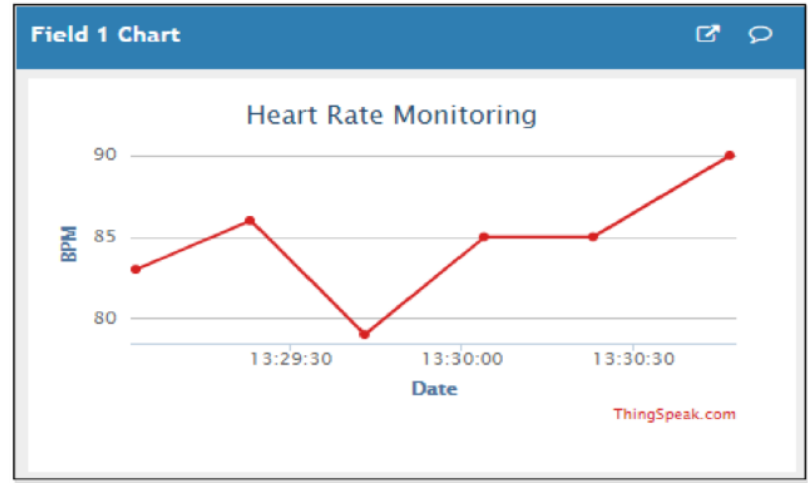

Figure 6. Heart rate monitor

Temperature sensor MLX90614 consists of four pins VDD, GND, SCL and SDA which is connected to arduino controller and output is displayed on LCD and alarm triggers if temperature and heart rate detects more or less value than normal range. Power is connected to $5 \mathrm{~V}$, ground is connected to GND whereas SCL and SDA are connected to analog. All of those components are connected and controlled mainly by arduino controller. Pushbutton is used which is reset when human being/object is detected. Figure 7 shows non-contact fever detection device.

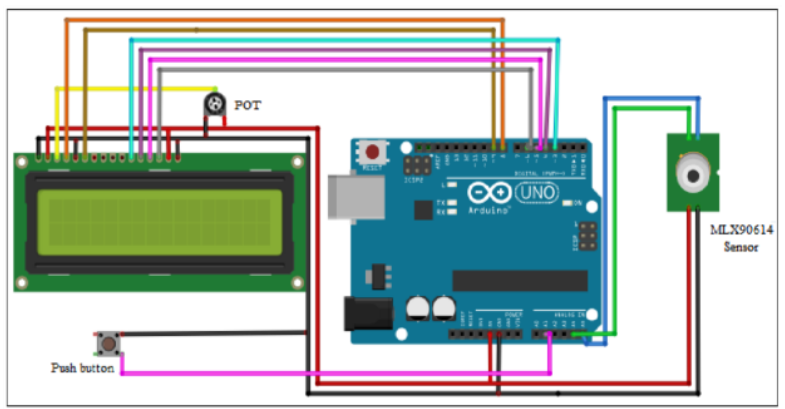

Figure 7. Non-contact fever detection device

For wireless communication wifi module is used which is connected with arduino board controller along with temperature sensor and resistors. Resistors are mainly used to restrict the flow of high currents in the circuit. Figure 8 shows Wifi module interfacing with arduino controller.

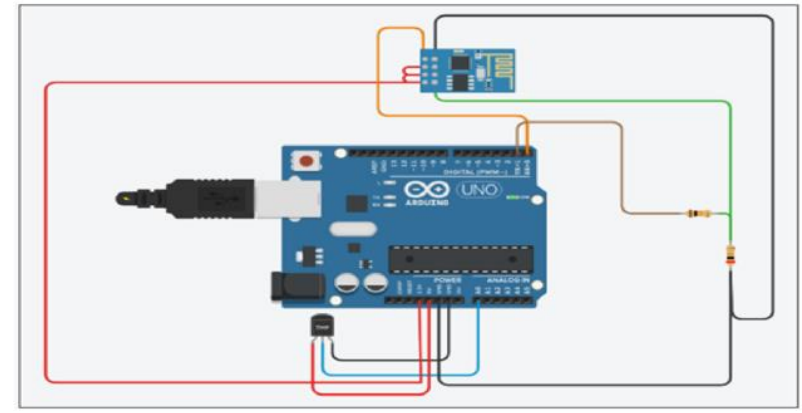

Figure 8. Wifi module interfacing with arduino controller

Temperature sensor consists of three pins: Vcc supply connected to $5 \mathrm{~V}$, Ground connected to GND and signal connected to analog Ao of the Arduino controller. Table 3 mentions the overall relation between wifi module, Arduino controller along with resistor values.

TABLE III

WIFI-MODULE CONNECTED TO ARDUINO CONTROLLER

\begin{tabular}{|l|l|l|}
\hline \multicolumn{1}{|c|}{ Wifi module } & \multicolumn{1}{|c|}{ Arduino } & \multicolumn{1}{c|}{$\begin{array}{c}\text { Resistor } \\
\text { values }\end{array}$} \\
\hline Transmitter,Tx & Receiver & $30 \mathrm{~K}$ \\
\hline- & Transmitter & $10 \mathrm{~K}$ \\
\hline Vcc supply & $3.3 \mathrm{~V}$ & - \\
\hline Reset & $3.3 \mathrm{~V}$ & - \\
\hline Channel enable & $3.3 \mathrm{~V}$ & - \\
\hline Ground & GND & $20 \mathrm{~K}$ \\
\hline
\end{tabular}


The code for the Arduino is mentioned to monitor the temperature. The output is monitored online through any smart devices. The code is written in Arduino 1.8.12 board and monitored the data online. Fig.14 a and b- Temperature sensor monitored along with Arduino controller.

The flowchart visualizes the process of detecting human body temperature (without contacting) with the help of MLX90614 sensor. If the human temperature is above the set temperature in the logic, then the individual is routed to the hospital for further process and if it's less than the set temperature limit then he would be granted entry. Flowchart is shown in figure 9 .

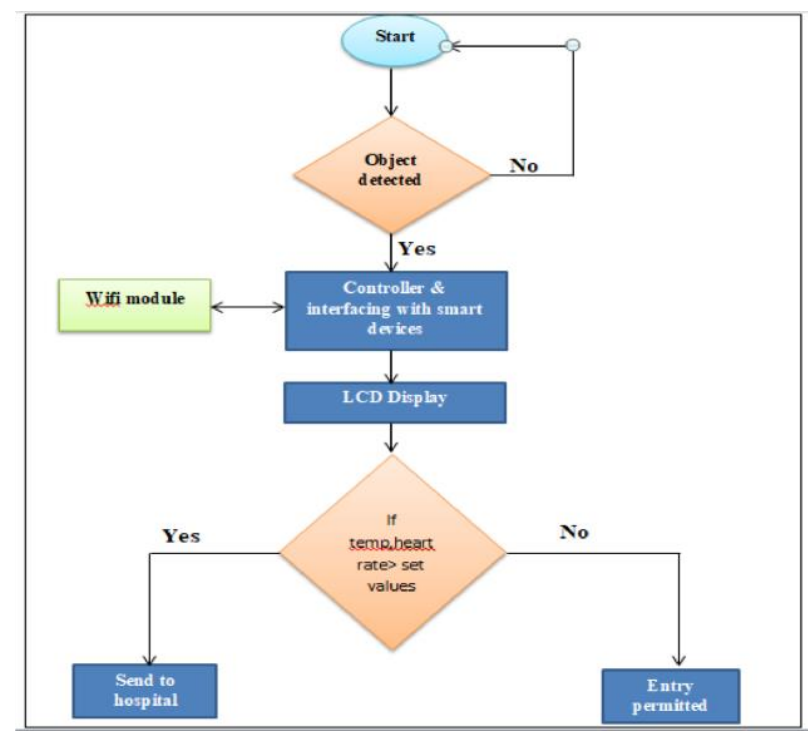

Figure 9. Flowchart

\section{CONCLUSION}

Regarding the overall research paper. The message is to bring a model-based framework focusing at micro level aspects, wherein emphasis is given to technologically advanced systems to be adapted by various organizations, Society and even individuals to contain the spread of virus thereby integrating technology in the day today activity by ways of implementation of the proposed system. This would surely help to focus on the aspects of dealing with the Virus post Lockdown, this also revolves around the precautionary measures on limiting the spread of the Virus. Further emphasizing on this model, it would also additionally benefit individuals to monitor their health status online for individual and suggestive purpose.

\section{REFERENCES}

[1] World Health Organization (WHO). 31st Dec 2003. https://www.biorxiv.org/content/10.1101/2020. 01.31.929547v1.full.pdf

[2] World Health Organization (WHO). 10th June 2013. https://www.who.int/mediacentre/news/ releases/2013/mers_cov_20130610/en/

[3] World Health Organization (WHO). Nov 2019 https://www.who.int/emergencies/mers-cov/en/

[4] World Health Organization (WHO). Coronavirus 2020 https://www.who.int/docs/defaultsource/coronaviruse/situatio n-reports/20200626-covid-19-sitrep158.pdf?sfvrsn=1d1aae8a_2

[5] Anushka Patil, Chetana Pawar, Neha Patil , Rohini Tambe, "Smart health monitoring system for animals", International Conference on Green Computing and Internet of Things (ICGCIoT), 2015. DOI: 10.1109/ICGCIoT.2015.73807 15.

[6] Neuman, Michael. R., "Measurement of Vital Signs: Temperature", IEEE Pulse, Sept/Oct 2010, pp. 40-49.

[7] Nina A. Gold, Taaha M. Mirza, Usha Avva, "Alcohol santizer", StatPearls Publishing LLC., 2021. https://www.ncbi.nlm.nih.gov/books/NBK513254/

[8] N. Radchenko, "A concept of the design and operation of heat exchangers with change of phase", Archives of Thermodynamics: Polish Academy of Sciences, 2004, vol.25, No.4, pp. 3-19.

[9] Ross B Kaplan, Timothy M Johnson, Ralf O Schneider, Shankar M Krishnan, “A design for low cost and scalable noncontact fever screening system", American Society for Engineering Education, 2011, pp. 2011-2830.

[10] Mayo Clinic Family Health Book, 4th edition and normal temperature. Available: https://www.pregnancybirthbaby.org.au/fever-in-babies

[11] Christopher Schmitz, Lindsey Drake, Megan Laake, Peng Yin, Rachel Pradarelli, "Physiological Response to Fear in Expected and Unexpected Situations on Heart Rate, Respiration Rate and Horizontal Eye Movements", Physiological Response of Fear in Expected and Unexpected Situations

[12] MLX90614 sensor.

https://www.digchip.com/datasheets/1110594mlx90614.html 
[13] Working of heartbeat sensor.

https://www.elprocus.com/heartbeat-sensor-circuit-daigramworkingwith-8051/

[14] Arduino board.

https://www.arduino.cc/en/Guide/ArduinoUno

[15] Wifi module.

https://quartzcomponents.com/products/esp8266-01-wifi-

module
[16] Touch less hand sanitizer.

https://circuitdigest.com/microcontroller-projects/automatichand-sanitizerdispenser-with-covid19-live-updates

[17] Ultrasonic sensor.

https://www.electroschematics.com/ultrasonic-sensor-circuit/ 